\title{
Semi-continous beam-to-column joints for slim-floor systems in seismic zones
}

\author{
C. Vulcu ${ }^{a}$, R. Don ${ }^{a}$ and A. Ciutina ${ }^{b^{*}}$ \\ aPolitehnica University of Timisoara, Dept. Steel Structures and Structural Mechanics, Romania \\ ${ }^{b}$ Politehnica University of Timisoara, Dept. Overland Communication Ways, Foundation and Cadastral \\ Survey, Romania \\ *corresponding author, e-mail address: adrian.ciutina@upt.ro
}

\begin{abstract}
The slim-floor building system is attractive to constructors and architects due to the integration of steel beam in the overall height of the floor, which leads to additional floorto-floor space, used mostly in acquiring additional storeys. The concrete slab offers natural fire protection for steel beams, while the use of novel corrugated steel sheeting reduces the concrete volume, and replaces the secondary beams (for usual spans of steel structures). Currently the slim-floor solutions are applied in non-seismic regions, and there are few studies that consider continuous or semi-continuous fixing of slim-floor beams. The present study was performed with the aim to develop reliable end-plate bolted connections for slimfloor beams, capable of being applicable to buildings located in areas with seismic hazard. It is based on numerical finite element analysis, developed in two stages. In a first stage, a finite element numerical model was calibrated based on a four point bending test of a slimfloor beam. Further, a case study was analysed for the investigation of beam-to-column joints with moment resisting connections between slim-floor beams and columns. The response was investigated considering both sagging and hogging bending moment. The results are analysed in terms of moment-rotation curve characteristics and failure mechanism.
\end{abstract}

Keywords: slim-floor; concrete-dowels; moment-resisting frames, beam-to-column joints.

\section{Introduction}

The structural solutions provided by the usage of composite elements are regarded as an effective method of enhancing structural performance. A series of advantages emerge as concrete, steel and additional components are integrated into a more resistant and ductile member (Arcelor-Mittal: "Slim Floor an innovative concept for floors" [1]). In particular, the slim-floor building system is attractive to constructors and architects due to the integration of steel beam in the overall height of the floor, which leads to additional floor-to-floor space, used mostly in acquiring additional stories. The concrete slab offers natural fire protection to the steel beams, while the use of novel corrugated steel sheeting reduces the concrete volume, and replaces the secondary beams (for usual spans).

The slim-floor solutions are currently applied mostly in non-seismic regions - [2], [3], and there are few studies that consider continuous or semi-continuous fixing of slim-floor beams. It was shown in [4], that the semi-continuous joining of slim-floor beams improves the flexural stiffness of the slim-floor beams and allows the use of shallower beam and floor sections, and better performance of beams in service conditions by reducing cracking, deflections and vibrational problems. In [5] and [6] it was shown that in case of increasing gravitational loads the continuous fixing of the slim-floor beams can lead to ductile plastic hinges in both beam-ends and middle spans. In contrast, the usual seismic behaviour rely on increased frame lateral stiffness and failure mechanisms by dissipation of seismic input energy by plasticization of dissipative elements or connections. Consequently, in case of Moment-Resisting-Frames (MRF) or dual frame configurations considering MRF contribution, the beams or the beam-to-column joints of MRF 
will dissipate energy through plastic hinges. Therefore, the application of slim-floor beam systems in seismic zones should consider moment-resisting connection with columns, thus developing hogging bending too. However, certain aspects characteristic for slim-floor systems should be considered (see Fig. 1):

- the concrete slab encases the top steel flange and needs one layer of hogging reinforcement;

- the natural bonding and/or the concrete dowels contribute significantly to steel-toconcrete connection. In many cases there is no need for additional connectors;

- bottom part of steel profile is larger than the top flange in order to accommodate the concrete supporting system: shallow decking or precast concrete slabs;

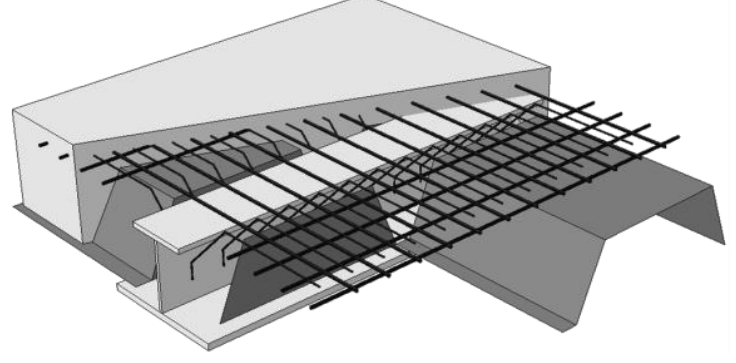

Fig. 1. Slim-floor system.

The present study investigates the possibility to develop reliable connections for slim-floor beams, in view of application to buildings located in areas with seismic hazard. The paper presents the finite element numerical investigations and the outcomes of the study. In a first stage, a finite element numerical model was calibrated based on a four point bending test of a simply supported slim-floor beam. Further, a case study was developed in view of investigation of continuous slim-floor beam-tocolumn connections under both sagging and hogging bending.

\section{FEM calibration of a slim-floor beam}

\subsection{Research background}

The numerical analysis of slim-floor beamto-column joints is based on an initial calibration of a finite element (FE) numerical model based on the experimental investigation as detailed in [2] on a four-point bending test of a slim-floor beam. This model was considered a comparison basis which appropriately checked the accuracy of the FEM models used for materials, contacts and boundary conditions further used in modelling the beam-to-column connection models. Thus, the information on the behaviour of a composite element, the steel-to-concrete friction coefficient, modelling procedure, importance of "concrete dowels" and reinforcement, meshing techniques and interactions were derived through calibration.

\subsection{Calibration of the numerical model}

The calibration of the numerical model was performed based on the data available in [2] presenting an experimental testing of an $8 \mathrm{~m}$ long slim-floor beam, tested in a 4-point-load arrangement, as shown in Fig. 2. The different components of the slim-floor beam are presented in Fig. 3. The complete technical information (geometry, boundary conditions, materials, etc.) is available in relevant documents [2], [3] and [7]. The numerical investigation was performed using Abaqus v6.13 finite element modelling software [8]. The material characteristics are defined within the numerical model for the following: concrete $(\mathrm{C} 30 / 37)$, structural steel (S355) and reinforcement bars (S450), based on the real mechanical characteristics provided by the authors. The elastic behaviour of the steel elements is described by: Young's modulus $\mathrm{E}=210000 \mathrm{~N} / \mathrm{mm} 2$ and Poisson's ratio $v=0.3$. The material plastic characteristics are illustrated in Fig. 4a. The concrete input characteristics in the elastic domain are: Young modulus $\mathrm{E}=32500$ $\mathrm{N} / \mathrm{mm}^{2}$ and Poisson ratio $v=0.2$. The plastic behaviour is defined by the stress-strain curve shown in Fig. $4 \mathrm{~b}$ by considering only compression characteristics and ignoring the tensile resistance.

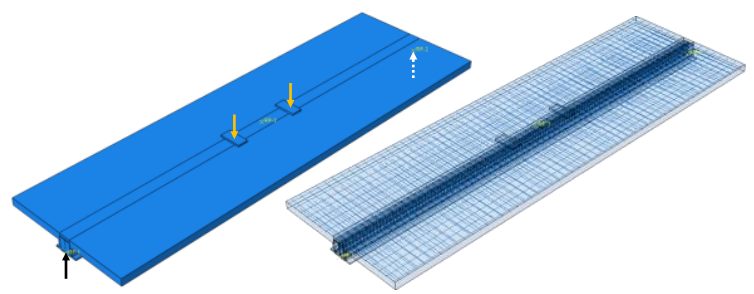

Fig. 2. Slim-floor beam - 3D view: static scheme; reinforcing bars arrangement

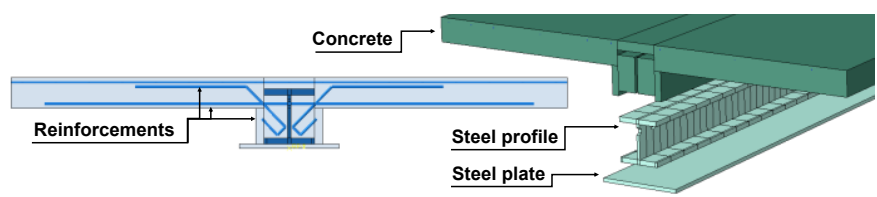

Fig. 3. Slim-floor beam components 


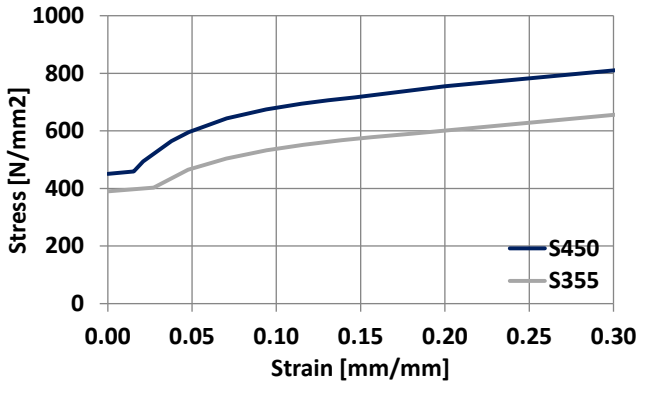

(a)

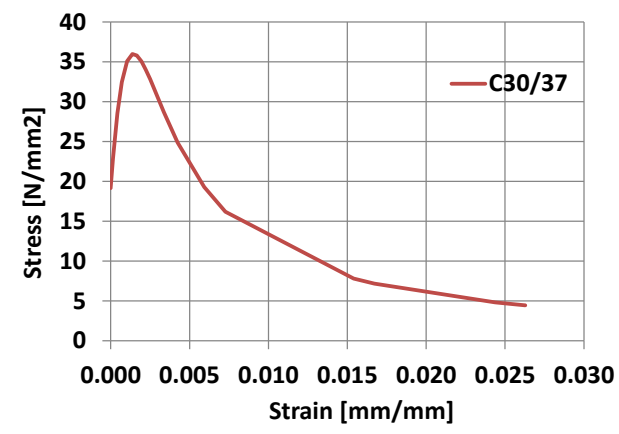

(b)

Fig. 4. Material model: (a) plastic true stress true strain curve for structural steel (S355) and reinforcing bars (S450); (b) stress-strain relationship for concrete

Three types of interactions were used for numerical model of the slim-floor beam, namely embedded, tie and rigid body. In order to replicate the interface behaviour of steel and concrete, an interaction law (and contact) was defined with a normal and tangential behaviour; The normal behaviour was assigned by "hard contact", which allows surface separation. The tangential behaviour was characterized by "penalty" with a friction coefficient $v=0.6$. The reinforcement was connected to the concrete part using the embedded constrained. The "Dynamic Explicit" type of analysis was considered due to the large amount of contact surfaces (e.g. between steel profile and the surrounding concrete). Contact problems were solved by using the "Dynamic Explicit" analysis, in contrast to the "Static General" analysis.

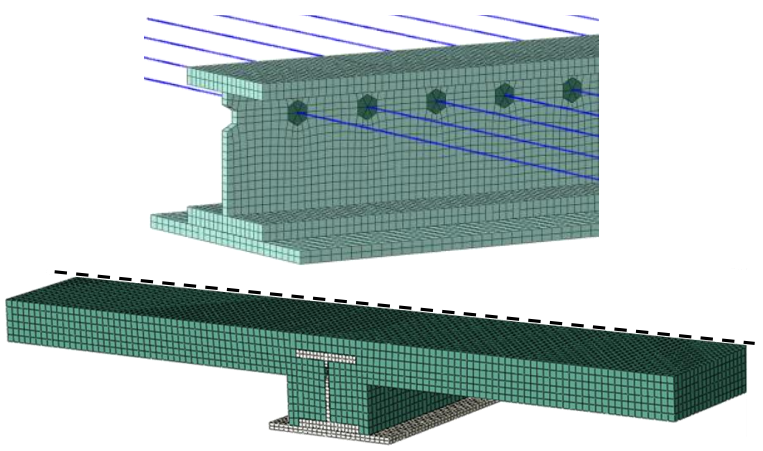

Fig. 5. Overall assembly view: mesh discretization
The following volume Finite Elements were used in the analysis: (i) B31 for reinforcing bars; (ii) C3D8R for steel profile, steel plates, concrete dowel and concrete. The global sizes of finite elements / mesh were adapted to different finite elements as follows: reinforcing bars $(30 \mathrm{~mm})$, concrete slab $(23 \mathrm{~mm})$, concrete dowel $(12 \mathrm{~mm})$, steel profile $(13 \mathrm{~mm})$, bottom steel plate $(18$ $\mathrm{mm})$, lateral steel plate $(13 \mathrm{~mm})$. An overall view of the meshed assembly is shown in Fig. 5.

\subsection{Calibration results}

The results of the numerical investigation are presented in terms of "bending moment vertical displacement" curve $(M-\delta)$ in Fig. 6a. The deformation of the slim-floor beam model is illustrated in Fig. 6b. As can be observed, the numerical model is able to accurately reproduce the response of the tested specimen, in terms of both initial stiffness and composite assembly's capacity. Corresponding to the horizontal plateau, the curves show less than $1 \%$ differences. Justified by the symmetrical loading and boundary conditions, the response is illustrated only for one half of the model. The stress distribution and plastic strain are also presented for the following components: concrete (Fig. 7a), steel profile (Fig. 7b) and respectively the reinforcing bars (Fig. 7c).
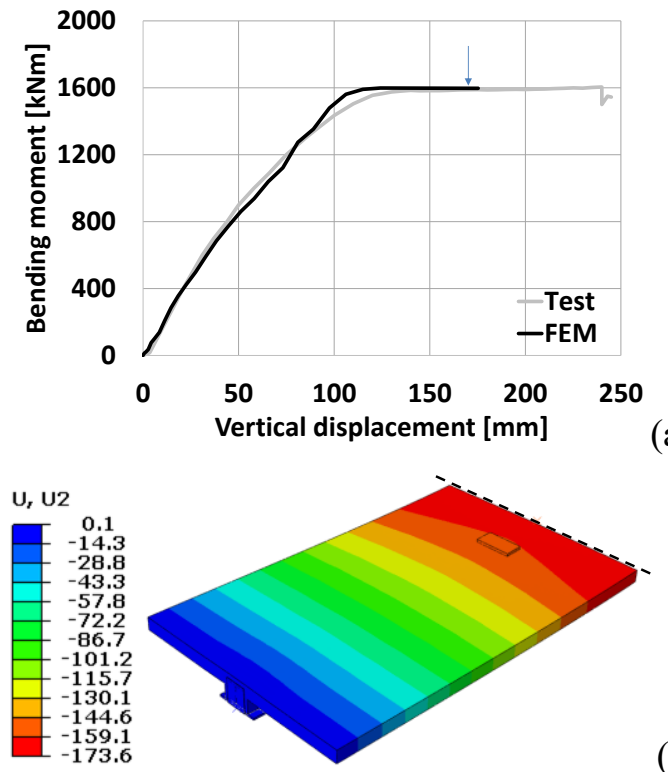

(a)

Fig. 6. Bending moment-vertical displacement curve $(\mathrm{M}-\delta)$, Vertical displacement

In Fig. $7 \mathrm{~b}$ it could be observed that the largest plastic deformations (strain) appear in the steel profile's bottom flange, including the welded steel plate, similar to the testing failure mode. 


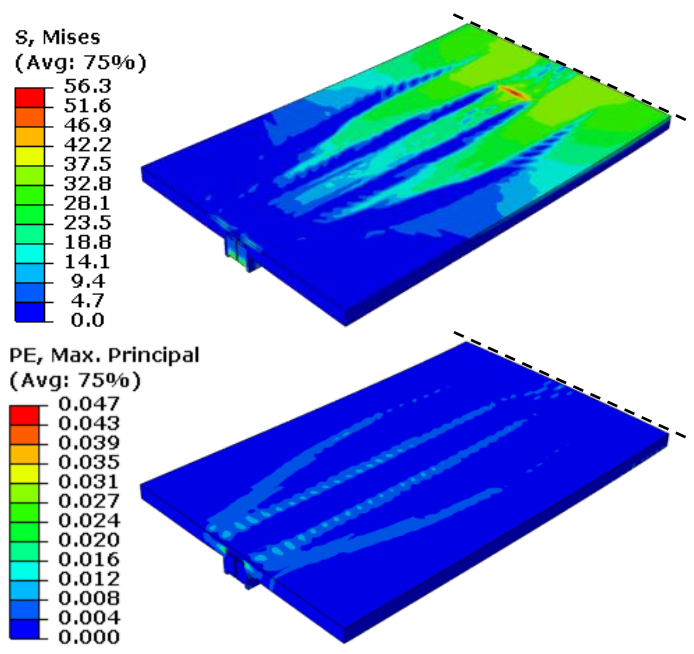

(a)

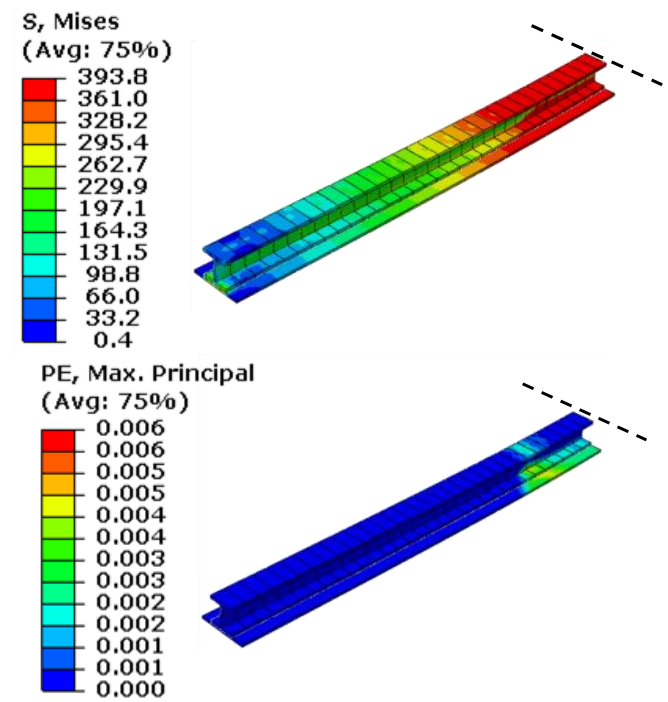

(b)

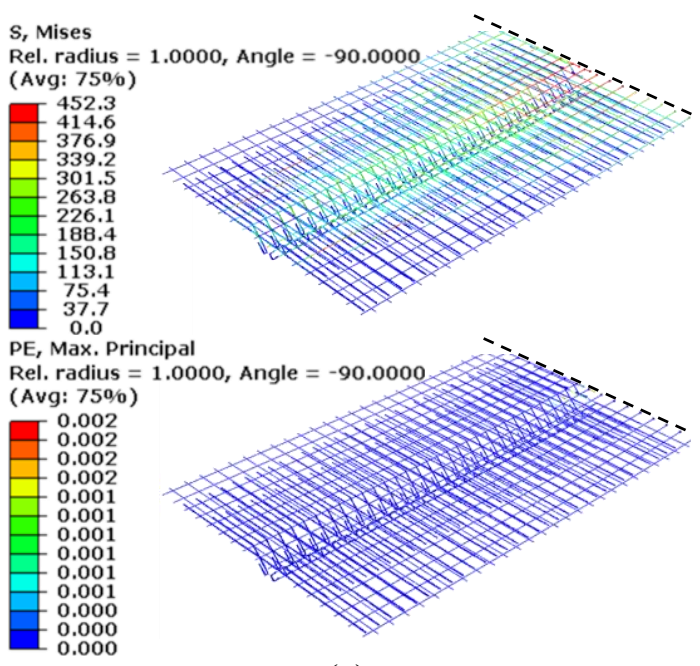

(c)

Fig. 7. Misses stress distribution and plastic strain in: (a) concrete, (b) steel profile,

(c) reinforcing bars and meshes

Fig. 7a shows the stress distribution and the plastic strain recorded in concrete slab.
Following the maximum bending formation, the maximum stresses are logically concentrated in the middle of the span. However, in addition to the mid-length stress concentration, longitudinal yielding appears nearby the supports, justified by the presence of shear force, absent between the two loading points.

Fig. $7 \mathrm{c}$ shows the stress distribution and the plastic strain in reinforcement bars. The maximum values are developed in the middle of the span. An important aspect of the numerical simulation, was to involve the reinforcing bars and steel meshes in the load transfer mechanism. The inclined bars contribute in high extent to the load transfer mechanism by connecting the concrete slab to the concrete located between the steel profile's flanges, therefore preventing the separation of the two. Moreover, the reinforcing bars passing through the web, together with the effect of concrete dowels, contribute to the composite action of the assembly.

\subsection{Calibration remarks}

The calibration of the slim-floor beam allowed to set various parameters related to the FE modelling. In addition, the numerical investigation has also allowed the assessment of the load transfer and failure mechanism. In particular, the assembly's failure mechanism resided in the formation of a plastic hinge in the mid span, justified by the large plastic deformations of the steel profile and the steel plate. The FE calibration of the behaviour of the slim-floor beam model revealed important modelling features such as:

- the finite element investigation of the slimfloor assembly implies modelling both of the transverse and longitudinal reinforcing bars, as well as the inclined reinforcing bars. The addition of the reinforcement bars to the model improves the assembly's overall behaviour by enhancing its load bearing capacity. The overall involvement of the reinforcing bars and steel meshes in the load transfer mechanism is obvious in this case;

- the inclined bars highly influenced the load transfer mechanism by connecting the concrete slab to the concrete located between the steel profile flanges, therefore preventing the separation of the two. The reinforcing bars passing through the web's perforations, together with the concrete dowels, contribute to the composite action of the assembly. 


\section{Numerical investigation of slim-floor beam-to-column connections}

\subsection{Configuration of the slim-floor beam-to- column joint}

The current study has the main purpose to propose a slim-floor beam-to-column joint configuration to be used in seismic resistant building frames, and to investigate its performance through numerical studies. The target was set on developing a continuous bolted connection, leading to the formation of the plastic hinge in the slim-floor beam. The proposed beam-to-column configuration is investigated under both sagging and hogging moments.

Fig. 8 shows the configuration of the investigated external beam-to-column joint assembly. In particular, the T-shape joint is composed of a slim-floor beam and a steel column. Fig. 8 shows the joint components, detailing concrete slab, reinforcement and steel components.

The concrete slab, integrating the steel beam and the reinforcement (transversal, longitudinal and inclined), considered a width of $1500 \mathrm{~mm}$ and a height of $145 \mathrm{~mm}$. The effective width computed according to the norm EN 1994-1 [10] was of $1200 \mathrm{~mm}$. The slab extension outside the column is of $600 \mathrm{~mm}$. Concrete in the bottom troughs has been ignored in the analysis and consequently not modelled. It is to be noted that the reinforcement bars considered in the analyses satisfy the reinforcement connection conditions required in the Annex C of EN 1998$1-1[11]$.

The steel column is a HEB340 profile, while the steel beam is composed by a bottom steel plate $(\mathrm{Pl}-20 \times 380 \mathrm{~mm})$ welded to half of an IPE600 profile. The column length is of 3930 $\mathrm{mm}$, while the beam length is $2680 \mathrm{~mm}$ distances equivalent to zones of zero-bending moments in a framed structure. A supplementary web plate and continuity plates were considered in the column web panel. Transversal, longitudinal and inclined reinforcement are used for the concrete slab (see Fig. 8). The continuity of the longitudinal reinforcing bars is assured around the column. In addition, the longitudinal reinforcing bars are included to contribute to the negative bending moment capacity within the connection zone. The connection between the slim-floor beam and the column is realized as bolted extended end-plate connection using four bolt rows of M36-HR.10.9 (see Fig. 8). Within the lower steel plate, a reduced cross-section was considered with the aim to force the development of the plastic hinge in the beam and assure a preponderant elastic response of the connection. Concrete dowels were considered similar to the configuration from Section 2, i.e. reinforcement of $12 \mathrm{~mm}$ diameter passing through $40 \mathrm{~mm}$ holes in the beam web. The centre-to-centre distances of the perforations is $125 \mathrm{~mm}$.
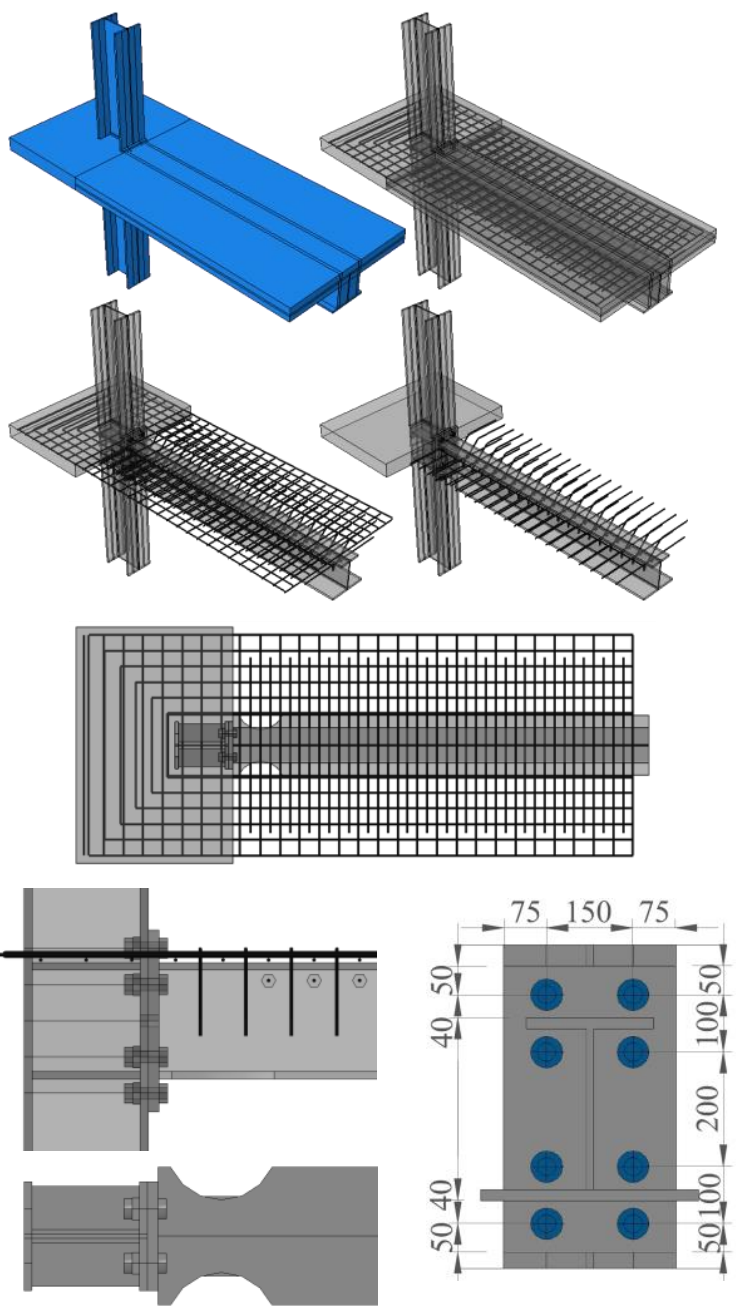

Fig. 8. Configuration of the beam-to-column joint model: overall joint, slab reinforcement, bolt rows and dog bone in lower steel plate

\subsection{Modelling procedure}

The numerical investigations of the slimfloor beam-to-column joint assembly (see Fig. 8) were performed by using Abaqus v6.13 software [8]. Finite beam elements were used for the reinforcement, and solid elements for other components (bolts, plates, concrete, etc.). The material characteristics were defined for the following: concrete (C30/37), structural steel 
(S355), bolts (HR. 10.9), and reinforcement bars (S400) considering both elastic and plastic properties. Fig. 9 illustrates the true stress - true strain curves (excepting elastic deformation) for bolts (HR.10.9), reinforcement (S460) and structural steel (S355). The material model for bolts was defined based on a previous calibration of a T-stub characterized by failure mode 3 (i.e. bolt failure), see 0 . For all steel elements the elastic modulus for steel was taken as $210 \mathrm{MPa}$, and the Poisson coefficient was 0.3 . The material models used to simulate the concrete and steel parts were similar to the models described in section 2. The global mesh size was adapted to different FE: reinforcing bars $-20 \mathrm{~mm}$; concrete - $18 \mathrm{~mm}$; steel profile - $14 \mathrm{~mm}$; bottom steel plate $-15 \mathrm{~mm}$; column $-13 \mathrm{~mm}$; end plate -10 $\mathrm{mm}$; column web plate and stiffeners $-12 \mathrm{~mm}$; bolts $-8 \mathrm{~mm}$. The discretization of the beam-tocolumn joint assembly and components is illustrated in Fig. 10. The boundary conditions for the column and beam considered: (i) at the top and bottom end of the column - a simple and respectively a fixed support; (ii) at the tip of the beam the load was applied in displacement control, inducing positive or negative bending moment within the connection zone.

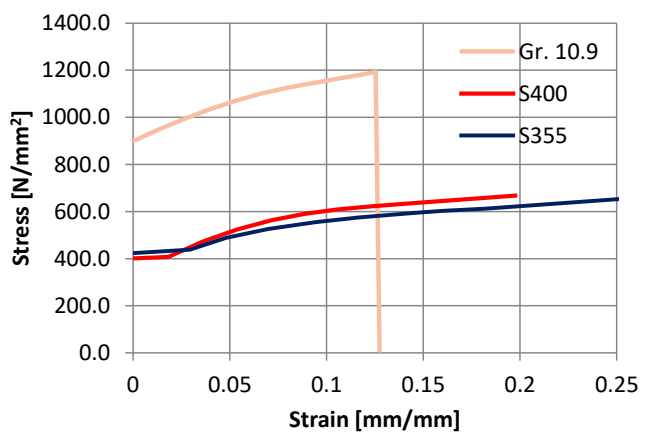

Fig. 9. True stress-strain curve: steel (S355), reinforcement (S400), bolts (Gr.10.9)

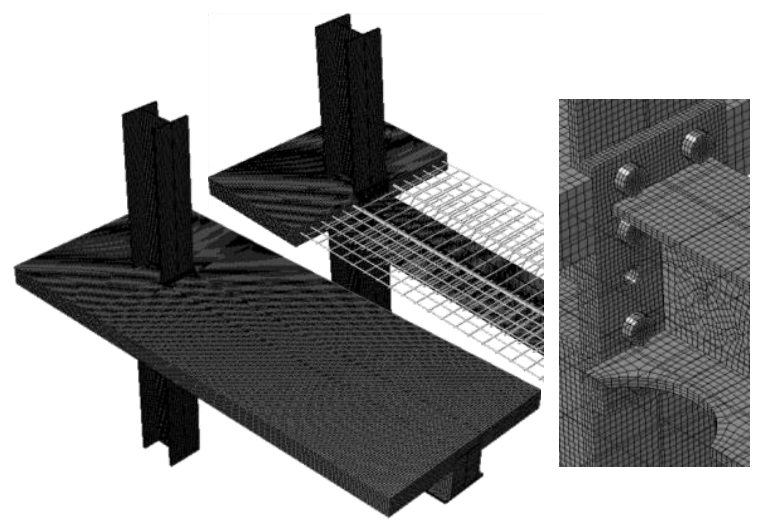

Fig. 10. Discretization of the beam-to-column joint assembly / connection

\subsection{Numerical results}

The numerical models of the beam-tocolumn joint assemblies were subjected to negative and positive bending moment. Table 1 shows an overview of the studied joint models.

Table 1. Investigated numerical models.

\begin{tabular}{|c|c|c|c|}
\hline No. & Description & \multicolumn{2}{|c|}{ Loading } \\
\hline M1 & Reference model & $\mathrm{M}+$ & M- \\
\hline M2 & $\begin{array}{l}\text { Influence of dog-bone, i.e. } \\
\text { joint model without dog-bone }\end{array}$ & $\mathrm{M}+$ & M- \\
\hline M3 & $\begin{array}{l}\text { Partial interaction - reduction } \\
\text { no. of concrete dowels }\end{array}$ & $\mathrm{M}+$ & M- \\
\hline M4 & $\begin{array}{l}\text { Influence of the end plate } \\
\text { type, i.e. flush plate at the top }\end{array}$ & & M- \\
\hline M5 & $\begin{array}{l}\text { Influence of the reinforcement } \\
\text { amount ( } 6 \text { / } 20 \mathrm{~mm} \text { diameter) }\end{array}$ & $\mathrm{M}+$ & M- \\
\hline M6 & $\begin{array}{l}\text { Influence of the concrete class } \\
\qquad(\mathrm{C} 20 / 25 ; \mathrm{C} 40 / 45)\end{array}$ & $\mathrm{M}+$ & M- \\
\hline
\end{tabular}

The outcomes of the numerical investigations are presented for the following configurations: (i) reference model (see Fig. 11 to Fig. 14); (ii) joint assembly without dog-bone in the lower steel plate (see Fig. 15 to Fig. 18). Results are presented in terms of: (i) moment-rotation curves under positive and negative bending (see Fig. 11 and Fig. 15); (ii) stress distribution and plastic strain (see Fig. 12, Fig. 13, Fig. 14, Fig. 16, Fig. 17 and Fig. 18).

The reference model presents a balanced behaviour under hogging and sagging (see Fig. 11) both in terms of moment resistance and initial stiffness, with a plastic descending behaviour but proving an important ductility. The failure mechanism was characterized by the formation of the plastic hinge in the steel beam under both sagging and hogging moment.

On the other hand, in case of the configuration without dog-bone (model M2), a small increase of capacity was evidenced under both positive and negative bending moment. However, under positive bending moment a brittle failure mode was recorded by failure of the bolts in tension, reducing the overall joint rotation capacity.

The joint resistance to hogging bending is directly influenced by the absence of the boltrow in the extended end-plate (model M4) by a reduction of $30 \%$. Also, the increase of the bar reinforcing diameter from 12 to $20 \mathrm{~mm}$ (Model M52) leads to an increase of resistance of 3\%, while a reduction of the reinforcing diameter to 


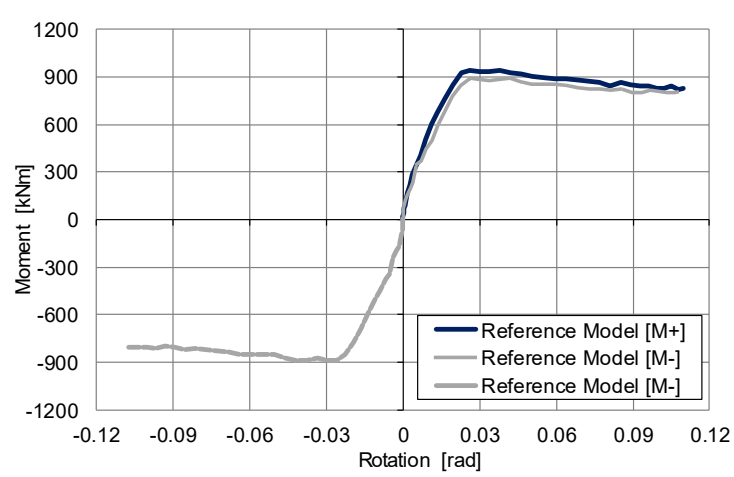

Fig. 11. Reference model M1: moment-rotation curves

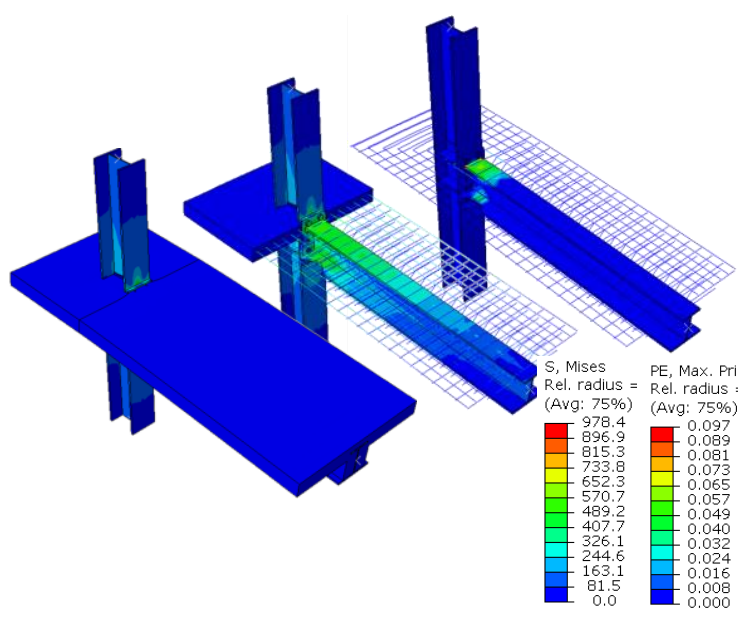

Fig. 12. Reference model M1: response under negative bending moment (stress/plastic strain)

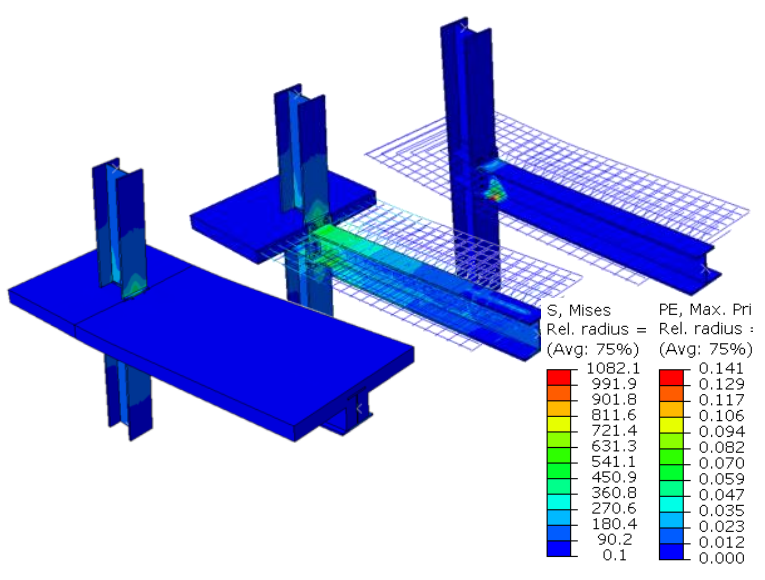

Fig. 13. Reference model M1: response under positive bending moment (stress/plastic strain)

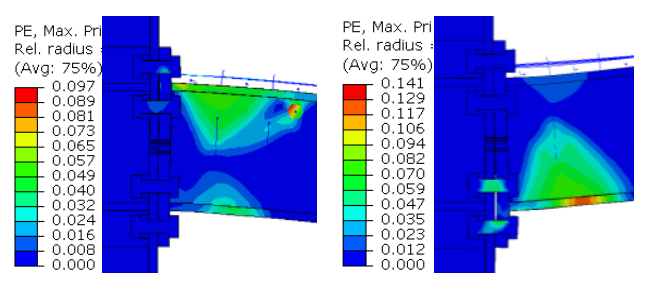

Fig. 14. Reference model: failure mechanism under negative and positive bending moment

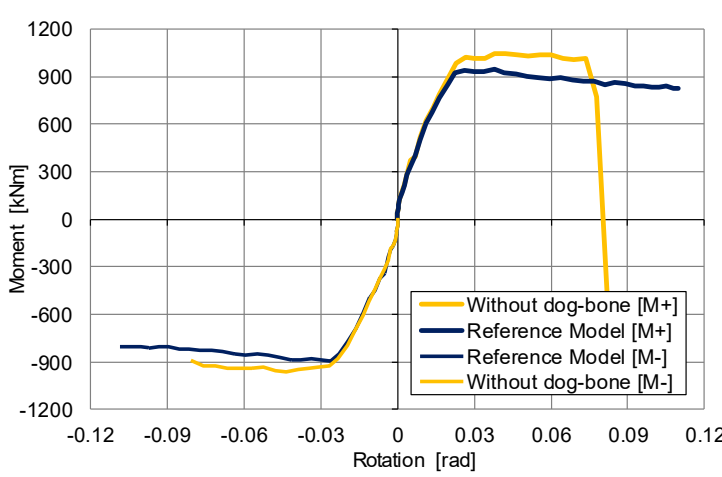

Fig. 15. Comparison between joint models M1 and $\mathrm{M} 2$

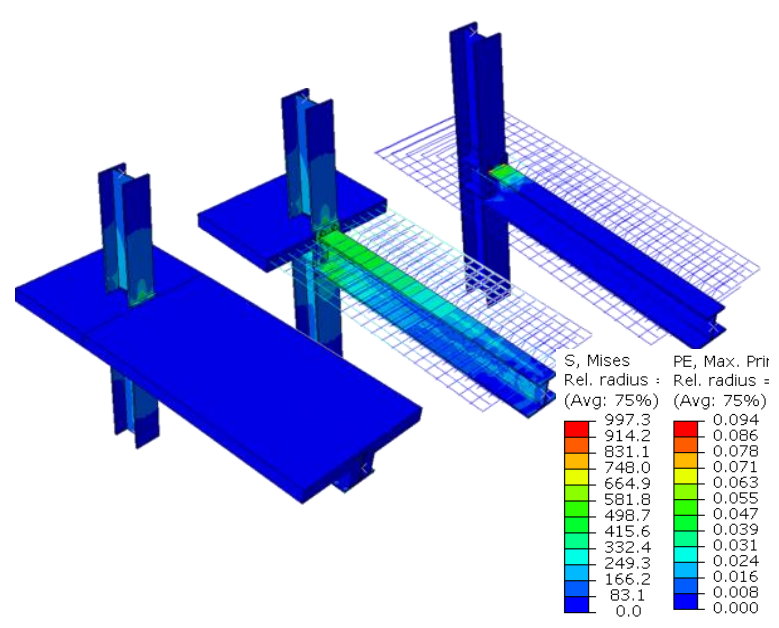

Fig. 16. Model without dog-bone M2: response under negative bending moment

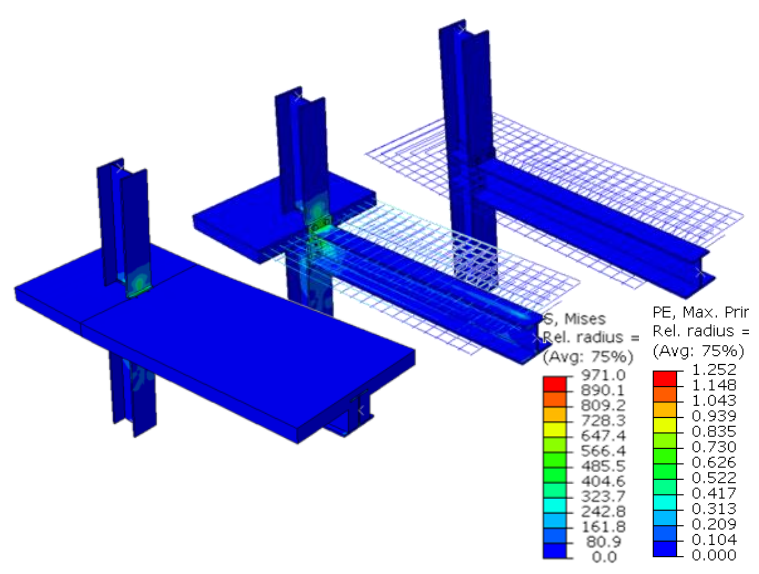

Fig. 17. Model without dog-bone M2: response under positive bending moment

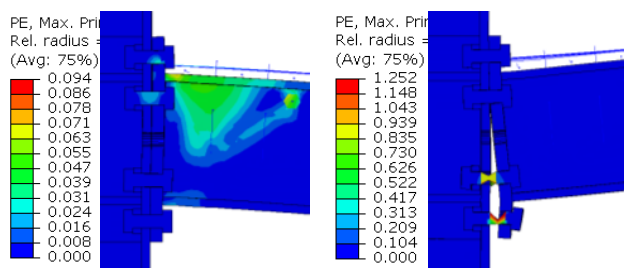

Fig. 18. Model without dog-bone: failure mechanism under negative and positive bending moment 
$6 \mathrm{~mm}$ (Model M51) is accompanied by a resistance reduction of $7 \%$.

On the other hand, the reduction of the number of concrete dowels (model M3) and the change in the concrete strength class have an insignificant influence on the global joint response (less than $2 \%$ ).

\section{Conclusions}

The current study was performed with the aim to develop reliable connections between slim-floor beams and columns - for application in structures located in seismic zones. In a first stage, a numerical model was calibrated based on a four point bending test of a slim-floor beam. The numerical calibration of the slim-floor beam allowed assessing the load transfer and failure mechanism (formation of plastic hinge at mid span). It proved the feasibility and performance of the steel-concrete connection, i.e. reinforcing bars passing through the profile's web and thus forming concrete dowels. In a second step a case study was performed for the investigation of slim-floor beam-to-column joint configurations. The FEM investigation on slim-floor beam-tocolumn joints lead to the following conclusions:

- in seismic regions it is possible to rely on the full or semi-continuity of joints in the global failure mechanism of MRF or dual steel structures with slim-floors;

- the influence of concrete slim-floor slab is effective in sagging bending as it contributes to the global increase of the both the stiffness and bending capacity. In hogging its influence is less important and the connection characteristics are mainly based on steel components;

- the failure mode of the joint configuration with dog-bone in the lower steel plate was characterized by a ductile formation of the plastic hinge in the beam. In contrast, the configuration without dog-bone lead to the failure of bolt rows in tension (brittle failure);

- the presence of the reinforced concrete slab lead to a limited increase of capacity and stiffness. The inclined reinforcement and the concrete dowels contributed to the load transfer mechanism by connecting the concrete slab to the concrete within flanges. A significant increase of longitudinal reinforcement will lead to higher capacity under negative bending moment.

Based on existing studies and the current study, it is proven that the slim-floor beams can be adapted to Seismic-Resistant Structures and the key aspect is related to the behaviour of slimfloor beam-to-column joints. Future research activities will involve experimental investigation as well as structural numerical analyses for improving the applicability of such systems.

\section{References}

[1] Arcelor Mittal. Slim-floor - innovative concept for floors. Long Carbon Europe Sections \& Merchant Bars.

[2] Hauf G. Trag- und Verformungsverhalten von Slim-Floor Trägern unter Biegebeanspruchung, 2010.

[3] Braun M, Obiala R, Odenbreit C, Hechler O. „Design and Application of a new Generation of Slim-Floor Construction", 7th European Conf. on Steel \& Composite Structures, Naples, Italy, 2014.

[4] Malaska M. Behaviour of a Semi-Continuous Beam-Column Connection for Composite Slim Floors, Ph.D. Thesis, Espoo, Finland, ISBN 95122-5224-4, 2000.

[5] Wang Y, Yang L, Shi Y, Zhang R. Loading capacity of composite slim frame beams, Journal of Constructional Steel Research 65, 2009.

[6] Bernuzzi C, Gadotti F, Zandonini R. Semicontinuity in slim floor steel-concrete composite systems, 1st European Conference on Steel Structures. Eurosteel, 1995.

[7] Braun M, Obiala R, and Odenbreit C. Analyses of the loadbearing behaviour of deep-embedded concrete dowels, CoSFB. Steel Construction, 8: 167-173. doi:10.1002 / stco.201510024, 2015.

[8] Abaqus v6.13 [Computer software]. Dassault Systèmes, Waltham, MA.

[9] Vulcu C, Don R, Ciutina A, Dubină D. Numerical investigation of moment-resisting slim-floor beam-to-column connections. 8th International Conference on Composite Construction in Steel and Concrete (CCVIII 2017), July 30 - August 2, 2017, Spring Creek Ranch in Jackson, Wyoming, 2017.

[10]CEN. EN 1994-1-1. Eurocode 4: Design of composite steel and concrete structures-Part 1: General rules and rules for building. Brussels, Belgium, 2004.

[11]CEN. EN 1998-1-1, Eurocode 8: Design of structures for earthquake resistance-Part 1: General rules, seismic actions and rules for buildings, Brussels, Belgium, 2004.

Dubina D, et al. High strength steel in seismic resistant building frames, Final Report Grant No. RFSR-CT-2009-00024, RFCS Publications, European Commission, Bruxelles, Belgium, 2015. 